\title{
Green remediation of tetracyclines in soil-water systems
}

\author{
Om Prakash Bansal
}

Chemistry Department, D.S. College, Aligarh, India; drop1955@gmail.com

Received 26 September 2013; revised 29 October 2013; accepted 9 November 2013

Copyright (C) 2013 Om Prakash Bansal. This is an open access article distributed under the Creative Commons Attribution License, which permits unrestricted use, distribution, and reproduction in any medium, provided the original work is properly cited.

\section{ABSTRACT}

The presence of tetracyclines in soil and surface water is an emerging concern. The present study was undertaken to investigate remediation of tetracylines (tetracycline (TC), oxytetracycline (OTC) and chlortetracycline (CTC)) from aqueous solution using vetiver grass, water lettuce, and sunflower and root exudates of water lettuce, sunflower and from soil by tomato, Indian mustard and carrot plant. The data of this study denote that vetiver grass, water lettuce, sunflower remedy tetracyclines from water. The remediation \% after 63 days of treatment was 87 61 for TC; 88 - 68 for OTC and 87 - 68 for CTC. The remediation of tetracyclines at lower concentration of antibiotics in presence of root exudates of water lettuce and sunflower was more than $99 \%$ and remediation was faster than water lettuce or sunflower. The remediation of tetracyclines from aqueous solution may be due to oxidation of -OH group(s) of tetracycline through a process that is thought to involve reactive oxygen intermediates and/or role of peroxidase enzyme. The plant crops viz., tomato, Indian mustard and carrot can remedy $41 \%-72 \%$ of amended tetracyclines. The maximum bioaccumulation of TC and CTC was in Indian mustard and OTC was maximally bioaccumulated in tomato.

Keywords: Soil; Antibiotics; Tetracycline; Chlortetracycline; Oxytetracycline; Remediation Root Exudates; Vetiver Grass; Sunflower

\section{INTRODUCTION}

Environmental pollution is a global problem that affects both the developing and developed countries [1]. To a large extent both human and natural processes con- tribute to environmental pollution and contaminants are commonly classified as either organic or inorganic. Common organic pollutants are pesticides, oil spills, personal care products and antibiotics.

Antibiotics since their inception are used not only for the treatment of infections in humans and animals but used as a food supplement to promote growth of animals [2] too. In terms of their production and usage worldwide, tetracycline antibiotics were in the second place in ranking order. Certain activities such as disposal of expired medicine in the sewage system, excretions of unmetabolized pharmaceuticals from humans and animals, discharge of wastewater and surface runoffs to receiving water [3,4], land application of biosolids and manure or disposal of biosolids at landfill can result in the dispersion of these compounds in the environment [5]. A number of researchers [6-8] during their studies reported detection of TCs at around $0.15 \mu \mathrm{g} \cdot \mathrm{L}^{-1}$ in ground and surface water, $86-199 \mu \mathrm{g} \cdot \mathrm{kg}^{-1}$ in soils, $4 \mathrm{mg} \cdot \mathrm{kg}^{-1}$ in liquid manure and $3 \mu \mathrm{g} \cdot \mathrm{L}^{-1}$ in farm lagoons.

Tetracyclines are complex organic compounds. Their structures contain four connected ring system with multiple ionizable functional groups and can exist as cationic, zwitterionic or anionic species under acidic, neutral and alkaline conditions respectively. The ionization behavior can be expected to significantly influence the persistence of tetracyclines in soils and surface and ground water. The persistence of antibiotics in soils has been reported to be influenced by adsorption, water content, temperature and soil composition $[9,10]$. The conventional methods used to biodegrade the antibiotics are sorption, hydrolysis, photolysis, oxidation and reduction [11]; however, there are some limitations associated with these methods. So, there is an urgent need for a useful biotic degradation method for remediation of tetracyclines from environment. The objective of this study was to develop a sustainable technique to remedy tetracyclines contaminated water using plants (vetiver grass, water lettuce, sunflower), their root exudates and soils 
using crops.

\section{MATERIALS AND METHODS}

Green house experiments were conducted in several glass tanks. The autoclaved double distilled water was mixed with $0.0676 \mathrm{~g}$ of $\mathrm{KH}_{2} \mathrm{PO}_{4}, 0.253 \mathrm{~g}$ of $\mathrm{KNO}_{3}, 0.59$ $\mathrm{g}$ of calcium nitrate and $0.2 \mathrm{~g}$ of magnesium chloride and the volume was made to $1 \mathrm{~L}$. In the first set of experiments $60 \mathrm{~g}$ of vetiver grass, water lettuce and sunflower were acclimatized in the solution for two weeks separately. $0-25 \mathrm{mg} / \mathrm{L}$ of tetracyclines solution (Tetracycline, oxytetracycline and chlortetracycline) were added to these tanks via a syringe. All the tanks were covered with aluminum foil to avoid photo degradation. In the second set of experiments the water tanks ( $1 \mathrm{~L}$ water) were amended with $5 \mathrm{~g}$ of root exudates of water lettuce and sunflower. 0 - $25 \mathrm{mg} / \mathrm{L}$ of tetracyclines solution (Tetracycline, oxytetracycline and chlortetracycline) were added to these tanks via a syringe. All the tanks were covered with aluminum foil to avoid photo degradation In the third set of experiments $4 \mathrm{~kg}$ of autoclaved soil samples with Clay $\%=13.4$, sand $\%=38.4$, silt $\%=48.2$, organic matter $\%=1.75, \mathrm{pH}(1: 2.5)=8.8$ and CEC $\left(\mathrm{mmol} \cdot \mathrm{kg}^{-1}\right)=11.4$ were amended with $5,10,15,20$ and $25 \mathrm{mg} \cdot \mathrm{kg}^{-1}$ soil of antibiotics were taken in several glazed earthenware pots. Four pregerminated seedlings of tomato (Lycopersicon esculentum), Indian mustard (Brassica juncea) and carrot (Daucus carota) were planted in each pots. These pots including blanks were also amended with $\mathrm{NH}_{4} \mathrm{NO}_{3}$; superphosphate and $\mathrm{KCl}$. The plants were harvested on 63 days after transplanting. The water and soil samples were sampled after $0 \mathrm{~d}(4 \mathrm{~h}), 2 \mathrm{~d}, 5 \mathrm{~d}, 7$ d, $14 \mathrm{~d}, 21 \mathrm{~d}, 35 \mathrm{~d}, 49 \mathrm{~d}$ and $63 \mathrm{~d}$ of treatments. The tetracyclines in samples were estimated as discussed elsewhere [12]. All the experiments were done in triplicate with suitable blanks.

\section{RESULTS AND DISCUSSION}

Remediation from water: The results of this study denote that vetiver grass, water lettuce and sunflower remediate tetracyclines from water. The amount of tetracycline remediated increased with increase in time of contact (Table 1). The \% removal after 63 days of treatment by vetiver grass was 87 - 72 for TC; 77 - 68 for OTC and 75 - 68 for CTC. Water lettuce remediates $71 \%$ - $61 \%$ of TC; $86 \%-72 \%$ of OTC and $87 \%-74 \%$ CTC while removal by sunflower was $84 \%-70 \%$ for TC; $88 \%-73 \%$ for OTC and $88 \%$ - 74\% for CTC after 63 days of treatment. The results denote that vetiver grass has greatest remediation property for TC and followed the order vetiver grass $>$ sunflower $>$ water lettuce. Water lettuce, while sunflower has most remediating affinity for OTC and remediation was in the order sunflower $>$ water let- tuce $>$ vetiver grass and water lettuce removes most efficiently CTC followed by sunflower. With increase in amount of antibiotics in water though the amounts of tetracyclines remediate from water increased, but the \% of removal decreased.

The remediation of tetracyclines was faster in presence of root exudates of water lettuce or sunflower than water lettuce or sunflower (Table 2). The amount of remediation increased up to 35 days of treatment after which it became almost constant. Almost complete removal of tetracylines occurs at lower concentration $(5 \mathrm{mg} / \mathrm{L})$. The remediation at highest studied concentration $(25 \mathrm{mg} / \mathrm{L})$ was approximately $85 \%$. Greatest remediation by root exudates of sunflower was of CTC, while OTC was most remediated by root exudates of water lettuce. The remediation of tetracyclines by may be due to extraction and metabolization of tetracyclines through a process that is thought to involve reactive oxygen intermediates [13]. The probable site of the oxidation is $\mathrm{OH}$ groups of tetracyclines. The faster remediation of tetracyclines by root exudates might be due to the role of peroxidase enzyme [14].

Remediation from soil: The results of remediation of tetracyclines from soil and bioaccumulation in the fruits of tomato, carrot and Indian mustard grown on soil amended with different amount of tetracyclines are given in Table 3. An examination of Table 3 denote that the remediation of tetracyclines in soil in presence of tomato, Indian mustard and carrot were $64-50 ; 68-51 ; 60 \%$ $44.8 \%$ for TC, 68 - 53; $64-49 ; 56 \%-41.8 \%$ for OTC and $60-48 ; 72-54 ; 64 \%$ - 47\% for CTC respectively. The results also denote that the remediation $\%$ decreased with increase in antibiotic concentration in soil. The concentration of TC in tomato, Indian mustard and carrot was (Table 3) 3.2 - 36; 4.2 - 43 and $2.8-29 \mu \mathrm{g} \cdot \mathrm{kg}^{-1}$ fresh weight respectively. While the concentration for OTC was 3.8 - 42; $3.5-36 ; 2.2-24 \mu \mathrm{g} \cdot \mathrm{kg}^{-1}$ fresh weight. The bioaccumulation of CTC was most in Indian mustard followed by tomato and carrot. The results imply that antibiotics remediation by plants depends on plant type $[15,16]$, the remediation of TC and CTC from was most by Indian mustrd plant and of OTC by tomato.

\section{CONCLUSION}

Our studies show that antibiotics TC, OTC and CTC are taken up by vetiver grass, water lettuce, sunflower and root exudates of water lettuce and sunflower from aqueous medium. The root exudates remedy tetracyclines more efficiently. Our results also denote that remediation of antibiotics from soil occurs by plants. Indian mustard plant bioaccumulate most TC and CTC while OTC is mostly accumulated in tomato plant. The amount of tetracyclines uptake by plants increased with the increase in antibiotic concentration in soil. 


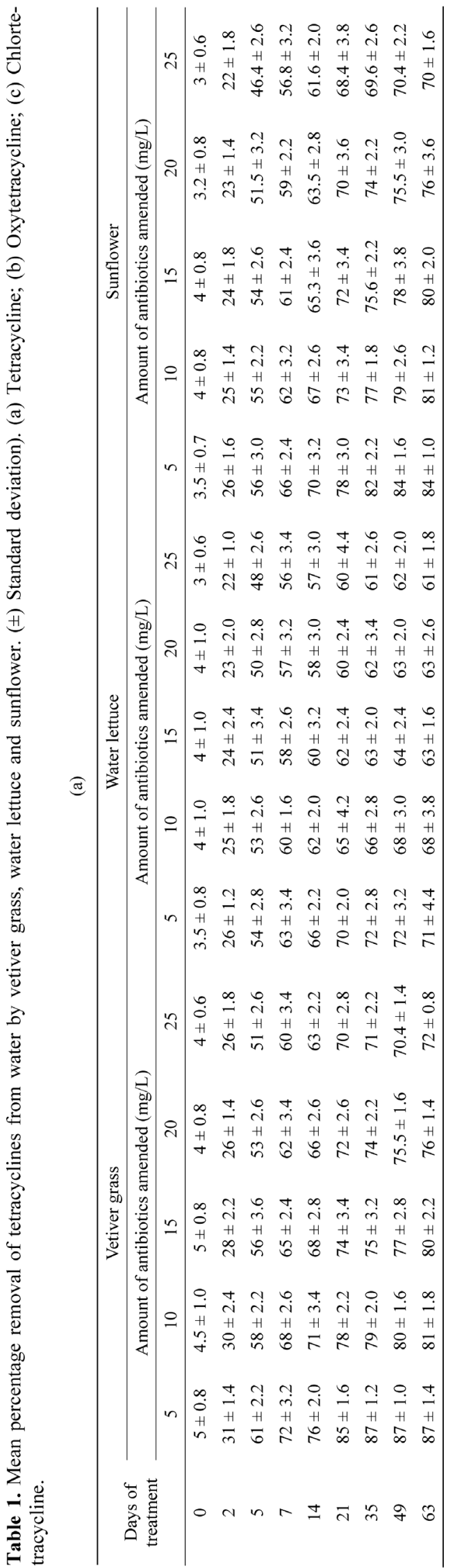

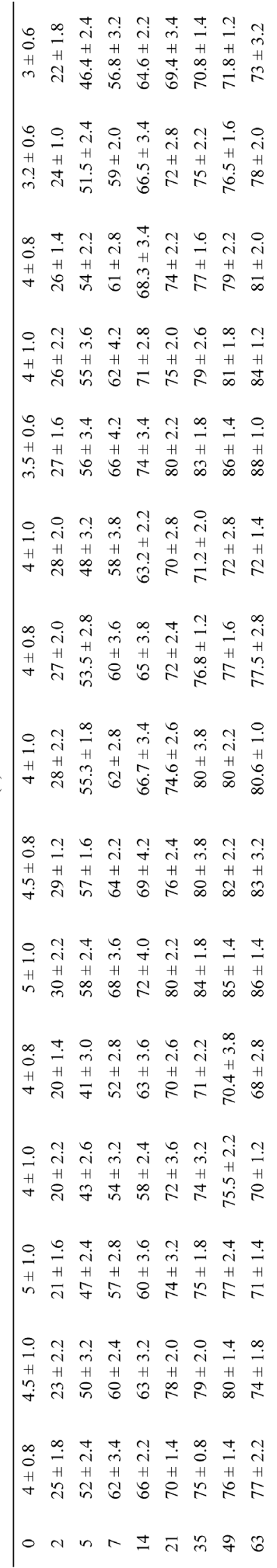

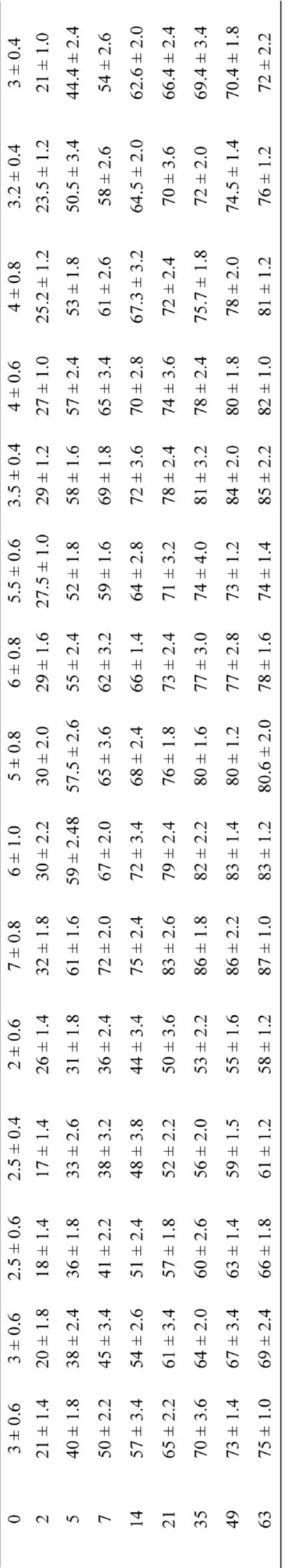


Table 2. Mean percentage removal of tetracyclines from water by root exudates of water lettuce and sunflower. (a) Tetracycline; (b) Oxytetracycline; (c) Chloretracycline.

(a)

\begin{tabular}{ccccccccccc}
\hline & \multicolumn{4}{c}{\begin{tabular}{c}
\multicolumn{3}{c}{ Root exudates of water lettuce } \\
Days of \\
treatment
\end{tabular}} & \multicolumn{3}{c}{ Amount of antibiotics amended (mg/L) } & \multicolumn{5}{c}{ Root exudates of sunflower } \\
\cline { 2 - 11 } & 5 & 10 & 15 & 20 & 25 & 5 & 10 & 15 & 20 & 25 \\
\hline 0 & $15 \pm 1.8$ & $13 \pm 1.4$ & $12 \pm 1.0$ & $12 \pm 1.8$ & $10 \pm 1.2$ & $16 \pm 1.4$ & $14 \pm 1.2$ & $13 \pm 1.4$ & $13 \pm 1.2$ & $10 \pm 1.0$ \\
2 & $45 \pm 2.4$ & $42 \pm 2.2$ & $38 \pm 1.6$ & $36 \pm 2.6$ & $33 \pm 3.4$ & $50 \pm 2.8$ & $48 \pm 2.4$ & $44 \pm 3.2$ & $42 \pm 3.2$ & $33 \pm 3.2$ \\
5 & $68 \pm 3.6$ & $64 \pm 3.8$ & $62 \pm 3.2$ & $60 \pm 3.4$ & $57 \pm 2.8$ & $72 \pm 2.2$ & $68 \pm 2.8$ & $65 \pm 2.8$ & $62 \pm 2.8$ & $57 \pm 2.6$ \\
7 & $79 \pm 4.0$ & $73 \pm 3.6$ & $70 \pm 2.8$ & $68 \pm 3.2$ & $65 \pm 3.8$ & $84 \pm 3.6$ & $79 \pm 3.2$ & $75 \pm 4.8$ & $72 \pm 3.4$ & $65 \pm 2.4$ \\
14 & $85 \pm 5.0$ & $80 \pm 4.2$ & $74 \pm 3.0$ & $70 \pm 3.4$ & $68 \pm 4.4$ & $88 \pm 3.2$ & $84 \pm 2.6$ & $78 \pm 4.0$ & $74 \pm 4.2$ & $68 \pm 4.2$ \\
21 & $94 \pm 2.4$ & $90 \pm 4.0$ & $85 \pm 3.2$ & $80 \pm 2.8$ & $77 \pm 5.2$ & $95 \pm 2.8$ & $90 \pm 2.8$ & $86 \pm 4.6$ & $82 \pm 5.2$ & $77 \pm 3.0$ \\
35 & $99 \pm 1.2$ & $95 \pm 3.4$ & $90 \pm 4.0$ & $84 \pm 3.8$ & $81 \pm 3.6$ & $99 \pm 1.0$ & $95 \pm 2.8$ & $92 \pm 5.2$ & $86 \pm 3.2$ & $81 \pm 2.8$ \\
49 & $99 \pm 0.8$ & $97 \pm 1.6$ & $92 \pm 3.8$ & $88 \pm 4.0$ & $85 \pm 4.4$ & $99 \pm 1.0$ & $97 \pm 2.0$ & $92 \pm 3.6$ & $88 \pm 4.4$ & $85 \pm 3.8$ \\
63 & $99 \pm 0.6$ & $97 \pm 2.2$ & $90 \pm 4.2$ & $87 \pm 4.4$ & $85 \pm 5.2$ & $99 \pm 1.4$ & $97 \pm 1.2$ & $92 \pm 3.0$ & $88 \pm 4.2$ & $85 \pm 2.4$ \\
\hline
\end{tabular}

(b)

\begin{tabular}{|c|c|c|c|c|c|c|c|c|c|c|}
\hline \multirow{3}{*}{$\begin{array}{l}\text { Days of } \\
\text { treatment }\end{array}$} & \multicolumn{5}{|c|}{ Root exudates of water lettuce } & \multicolumn{5}{|c|}{ Root exudates of sunflower } \\
\hline & \multicolumn{5}{|c|}{ Amount of antibiotics amended (mg/L) } & \multicolumn{5}{|c|}{ Amount of antibiotics amended (mg/L) } \\
\hline & 5 & 10 & 15 & 20 & 25 & 5 & 10 & 15 & 20 & 25 \\
\hline 0 & $12 \pm 0.8$ & $13 \pm 0.6$ & $12 \pm 1.0$ & $12 \pm 0.8$ & $10 \pm 1.2$ & $16 \pm 0.8$ & $14 \pm 1.2$ & $13 \pm 1.4$ & $13 \pm 1.0$ & $12 \pm 1.4$ \\
\hline 2 & $43 \pm 1.2$ & $40 \pm 1.8$ & $38 \pm 2.4$ & $35 \pm 2.0$ & $30 \pm 2.6$ & $52 \pm 2.2$ & $50 \pm 3.2$ & $46 \pm 2.4$ & $44 \pm 2.8$ & $36 \pm 2.0$ \\
\hline 5 & $66 \pm 2.4$ & $62 \pm 2.8$ & $60 \pm 3.4$ & $62 \pm 3.0$ & $55 \pm 4.4$ & $74 \pm 3.4$ & $70 \pm 2.6$ & $67 \pm 3.0$ & $64 \pm 3.4$ & $58 \pm 2.8$ \\
\hline 7 & $75 \pm 3.2$ & $71 \pm 3.4$ & $72 \pm 2.6$ & $70 \pm 3.6$ & $65 \pm 3.6$ & $85 \pm 4.2$ & $81 \pm 3.8$ & $78 \pm 3.6$ & $74 \pm 2.8$ & $68 \pm 3.2$ \\
\hline 14 & $89 \pm 2.8$ & $85 \pm 2.8$ & $80 \pm 2.2$ & $76 \pm 2.4$ & $72 \pm 2.4$ & $90 \pm 3.4$ & $87 \pm 2.8$ & $82 \pm 3.8$ & $78 \pm 2.2$ & $72 \pm 2.4$ \\
\hline 21 & $97 \pm 1.8$ & $92 \pm 2.4$ & $87 \pm 2.6$ & $83 \pm 1.8$ & $79 \pm 3.2$ & $96 \pm 2.0$ & $92 \pm 3.4$ & $88 \pm 3.6$ & $84 \pm 4.2$ & $78 \pm 2.8$ \\
\hline 35 & $99 \pm 0.8$ & $96 \pm 1.6$ & $92 \pm 2.2$ & $88 \pm 2.2$ & $85 \pm 1.8$ & $99 \pm 0.8$ & $97 \pm 1.6$ & $93 \pm 4.0$ & $87 \pm 3.2$ & $84 \pm 2.4$ \\
\hline 49 & $99 \pm 1.0$ & $97 \pm 1.2$ & $92 \pm 2.4$ & $88 \pm 1.6$ & $85 \pm 2.0$ & $99 \pm 1.2$ & $97 \pm 1.84$ & $93 \pm 3.2$ & $88 \pm 2.6$ & $85 \pm 4.2$ \\
\hline 63 & $100 \pm 0.0$ & $98 \pm 0.8$ & $92 \pm 3.6$ & $88 \pm 1.4$ & $85 \pm 2.4$ & $99 \pm 0.8$ & $97 \pm 2.2$ & $92 \pm 3.0$ & $88 \pm 2.2$ & $85 \pm 3.8$ \\
\hline
\end{tabular}

(c)

\begin{tabular}{|c|c|c|c|c|c|c|c|c|c|c|}
\hline \multirow{3}{*}{$\begin{array}{l}\text { Days of } \\
\text { treatment }\end{array}$} & \multicolumn{5}{|c|}{ Root exudates of water lettuce } & \multicolumn{5}{|c|}{ Root exudates of sunflower } \\
\hline & \multicolumn{5}{|c|}{ Amount of antibiotics amended (mg/L) } & \multicolumn{5}{|c|}{ Amount of antibiotics amended (mg/L) } \\
\hline & 5 & 10 & 15 & 20 & 25 & 5 & 10 & 15 & 20 & 25 \\
\hline 0 & $16 \pm 1.2$ & $14 \pm 0.8$ & $13 \pm 1.0$ & $13 \pm 0.8$ & $12 \pm 1.0$ & $16 \pm 1.0$ & $15 \pm 1.2$ & $13 \pm 0.8$ & $12 \pm 0.8$ & $12 \pm 1.0$ \\
\hline 2 & $50 \pm 2.8$ & $46 \pm 2.0$ & $43 \pm 2.8$ & $40 \pm 1.4$ & $38 \pm 2.2$ & $52 \pm 2.0$ & $50 \pm 2.2$ & $45 \pm 1.4$ & $43 \pm 1.8$ & $37 \pm 1.4$ \\
\hline 5 & $70 \pm 2.6$ & $66 \pm 2.6$ & $63 \pm 3.6$ & $60 \pm 2.4$ & $56 \pm 2.0$ & $74 \pm 2.2$ & $68 \pm 2.6$ & $65 \pm 2.2$ & $62 \pm 2.4$ & $58 \pm 2.8$ \\
\hline 7 & $82 \pm 3.4$ & $75 \pm 3.8$ & $72 \pm 4.2$ & $68 \pm 3.2$ & $64 \pm 3.2$ & $85 \pm 3.4$ & $80 \pm 2.4$ & $74 \pm 3.2$ & $70 \pm 1.8$ & $64 \pm 3.6$ \\
\hline 14 & $88 \pm 4.2$ & $84 \pm 3.4$ & $80 \pm 4.4$ & $75 \pm 3.8$ & $70 \pm 2.6$ & $92 \pm 1.8$ & $88 \pm 3.6$ & $84 \pm 3.6$ & $80 \pm 2.4$ & $76 \pm 3.4$ \\
\hline 21 & $94 \pm 2.2$ & $90 \pm 2.8$ & $85 \pm 3.2$ & $80 \pm 3.4$ & $76 \pm 3.2$ & $97 \pm 1.2$ & $94 \pm 2.2$ & $90 \pm 2.8$ & $86 \pm 3.4$ & $82 \pm 4.2$ \\
\hline 35 & $98 \pm 1.0$ & $94 \pm 2.4$ & $90 \pm 2.4$ & $85 \pm 4.2$ & $82 \pm 4.0$ & $100 \pm 0.0$ & $98 \pm 1.1$ & $94 \pm 2.4$ & $90 \pm 2.8$ & $86 \pm 3.2$ \\
\hline 49 & $98 \pm 1.2$ & $95 \pm 2.0$ & $90 \pm 2.2$ & $86 \pm 3.2$ & $82 \pm 3.2$ & $100 \pm 0.0$ & $98 \pm 1.0$ & $94 \pm 2.0$ & $90 \pm 3.2$ & $86 \pm 2.4$ \\
\hline 63 & $98 \pm 0.6$ & $95 \pm 2.2$ & $92 \pm 2.4$ & $86 \pm 2.4$ & $82 \pm 3.6$ & $100 \pm 0.0$ & $98 \pm 0.8$ & $94 \pm 2.4$ & $90 \pm 2.6$ & $86 \pm 2.6$ \\
\hline
\end{tabular}


Table 3. Mean concentration of tetracyclines in soils and plants $\left(\mu \mathrm{g} \cdot \mathrm{kg}^{-1}\right)$.

(a)

\begin{tabular}{|c|c|c|c|c|c|c|}
\hline \multirow{2}{*}{ Fortification of antibiotics $(\mathrm{mg} / \mathrm{kg}$ ) soil } & \multicolumn{3}{|c|}{ Soil after removal of plants (mg/kg soil) } & \multicolumn{3}{|c|}{ Tomato $(\mu \mathrm{g} / \mathrm{kg})$ fresh weight basis } \\
\hline & $\mathrm{TC}$ & OTC & CTC & $\mathrm{TC}$ & OTC & CTC \\
\hline 5 & $1.8 \pm 0.1$ & $1.6 \pm 0.08$ & $2.0 \pm 0.06$ & $3.2 \pm 0.16$ & $3.8 \pm 0.06$ & $2.7 \pm 0.14$ \\
\hline 10 & $3.8 \pm 0.16$ & $3.4 \pm 0.14$ & $4.2 \pm 0.14$ & $7.4 \pm 0.28$ & $9.3 \pm 0.12$ & $6.6 \pm 0.16$ \\
\hline 15 & $6.9 \pm 0.24$ & $6.4 \pm 0.18$ & $7.4 \pm 0.12$ & $13.2 \pm 0.34$ & $17.9 \pm 0.22$ & $11.4 \pm 0.28$ \\
\hline 20 & $9.2 \pm 0.26$ & $8.7 \pm 0.22$ & $9.6 \pm 0.20$ & $24 \pm 0.44$ & $29.6 \pm 0.64$ & $20.2 \pm 0.18$ \\
\hline 25 & $12.4 \pm 0.26$ & $11.8 \pm 0.34$ & $13 \pm 0.28$ & $36 \pm 0.32$ & $42 \pm 0.56$ & $31.5 \pm 0.38$ \\
\hline
\end{tabular}

(b)

\begin{tabular}{cccccccc}
\hline \multirow{2}{*}{ Fortification of antibiotics $(\mathrm{mg} / \mathrm{kg})$ soil } & \multicolumn{2}{c}{ Soil after removal of plants $(\mathrm{mg} / \mathrm{kg}$ soil $)$} & \multicolumn{3}{c}{ Lettuce $(\mu \mathrm{g} / \mathrm{kg})$ fresh weight basis } \\
\cline { 2 - 7 } & TC & OTC & CTC & TC & OTC & CTC \\
\hline 5 & $1.7 \pm 0.14$ & $1.8 \pm 0.12$ & $1.4 \pm 0.08$ & $4.2 \pm 0.14$ & $3.5 \pm 0.10$ & $5 \pm 0.08$ \\
10 & $3.4 \pm 0.18$ & $3.7 \pm 0.24$ & $3.2 \pm 0.18$ & $9.8 \pm 0.26$ & $7.8 \pm 0.16$ & $12.2 \pm 0.14$ \\
15 & $6.8 \pm 0.32$ & $7.0 \pm 0.26$ & $6.4 \pm 0.12$ & $18.6 \pm 0.38$ & $14.5 \pm 0.22$ & $22.4 \pm 0.22$ \\
20 & $9.0 \pm 0.28$ & $9.4 \pm 0.34$ & $8.6 \pm 0.24$ & $29 \pm 0.32$ & $24 \pm 0.42$ & $33.8 \pm 0.28$ \\
25 & $12.2 \pm 0.40$ & $12.8 \pm 0.52$ & $11.5 \pm 0.38$ & $43 \pm 0.44$ & $36 \pm 0.34$ & $52 \pm 0.36$ \\
\hline
\end{tabular}

(c)

\begin{tabular}{cccccccc}
\hline \multirow{2}{*}{ Fortification of antibiotics $(\mathrm{mg} / \mathrm{kg})$ soil } & \multicolumn{2}{c}{ Soil after removal of plants $(\mathrm{mg} / \mathrm{kg}$ soil) } & \multicolumn{3}{c}{ Carrot $(\mu \mathrm{g} / \mathrm{kg})$ fresh weight basis } \\
\cline { 2 - 7 } & TC & OTC & CTC & TC & OTC & CTC \\
\hline 5 & $2.0 \pm 0.06$ & $2.2 \pm 0.08$ & $1.8 \pm 0.10$ & $2.8 \pm 0.08$ & $2.2 \pm 0.16$ & $3.2 \pm 0.14$ \\
10 & $4.2 \pm 0.14$ & $4.5 \pm 0.12$ & $4.0 \pm 0.16$ & $5.4 \pm 0.14$ & $4.5 \pm 0.22$ & $7.8 \pm 0.18$ \\
15 & $7.4 \pm 0.24$ & $7.8 \pm 0.22$ & $7.1 \pm 0.20$ & $10.2 \pm 0.36$ & $8.4 \pm 0.26$ & $15 \pm 0.32$ \\
20 & $10.6 \pm 0.32$ & $11.2 \pm 0.18$ & $10.2 \pm 0.28$ & $19.2 \pm 0.32$ & $15 \pm 0.20$ & $23 \pm 0.24$ \\
25 & $13.8 \pm 0.26$ & $14.6 \pm 0.34$ & $13.2 \pm 0.24$ & $29 \pm 0.44$ & $24 \pm 0.34$ & $38 \pm 0.42$ \\
\hline
\end{tabular}

( \pm ) Standard deviation; TC $=$ Tetracycline; OTC $=$ oxytetracycline; $\mathrm{CTC}=$ Chlortetracycline.

\section{ACKNOWLEDGEMENTS}

The author expresses his sincere thanks to The University Grants Commission, New Delhi for financial assistance.

\section{REFERENCES}

[1] Suresh, B. and Ravishankar, G.A. (2004) Phtoremediation a novel and promising approach for environmental cleanup. Critical Reviews in Biotechnology, 24, 97-124. http://dx.doi.org/10.1080/07388550490493627

[2] Aust, M.O., Godlinski, F., Travis, G.R., et al. (2008) Distribution of sulfamethazine, chlortetracyclineand tysoline in manure and soil of Canadian feedlots after sub therapeutic use in cattle. Environmental Pollution, 156, 12431251. http://dx.doi.org/10.1016/j.envpol.2008.03.011

[3] Yang, S., Cha, J. and Carlson, K. (2005) Simultaneous extraction and analysis of 11 Tetracycline and sulfona- mide antibiotics in influent and effluent domestic wastewater by solid phase extraction and liquid chromatogramphy-Electro spray ionization tandem mass spectrometry. Journal of Chromatography, A1097, 40-53. http://dx.doi.org/10.1016/j.chroma.2005.08.027

[4] Gulkowska, A., Leung, H.W., So, M.K., et al. (2008) Removal of antibiotics from wastewater by sewage treatment facilites in Hong Kong and Shenzhen, China. Water Research, 42, 395-403. http://dx.doi.org/10.1016/j.watres.2007.07.031

[5] Kemper, N. (2008) Veterinary antibiotics in the aquatic and terrestrial environment-A review. Ecological Indica, 8, 1-13. http://dx.doi.org/10.1016/j.ecolind.2007.06.002

[6] Diaz-Cruz, M.S., de Alda, M.J.L. and Barcelo, D. (2006) Determination of antimicrobials in sludge from infiltration basins at two artificial recharge plants by pressurized liquid extraction-liquid Chromatography-tandem mass spectrometry. Journal of Chromatography, A1130, 72-82. 
http://dx.doi.org/10.1016/j.chroma.2006.05.076

[7] Segura, P.A., Francois, M., Gagon, C., et al. (2009) Review of the occurrence of anti-infectives in contaminated waste waters and natural and drinking waters. Environmental Health Perspective, 117, 675-684. http://dx.doi.org/10.1289/ehp.11776

[8] Liu, H., Yang, Y., Kang, J., et al. (2012) Removal of tetracycline from water by Fe-Mn binary oxide. Journal of Environmental Sciences, 24, 242-247. http://dx.doi.org/10.1016/S1001-0742(11)60763-8

[9] Aristidle, L., Marichal,C., Miehe-Brendle, J., et al. (2010) Interactions of oxytetracyclines with a smectite clay: A spectroscopic study with molecular simulations. Environmental Science and Technology, 44, 7839-7845. http://dx.doi.org/10.1021/es102136y

[10] Carrasquillo, A.J., Bruland, G.L., Mackay, A.A., et al. (2008) Sorption of ciprofloxacin and oxytetracycline zwitterions to soils and soil minerals: Influence of compound structure. Environmental Science and Technology, 42, 7634-7642. http://dx.doi.org/10.1021/es801277y

[11] Karc1, A. and Balcıoğlu, I.A. (2009) Investigation of the tetracycline, sulfonamide and fluoroquinolone antimicrobial compounds in animal manure and agricultural soils of Turkey. Science of the Total Environment, 407, 46524664. http://dx.doi.org/10.1016/j.scitotenv.2009.04.047

[12] Bansal, O.P. (2012) Sorption of Tetracycline and chlortetracycline on Na-, $\mathrm{K}$ - and $\mathrm{Ca}$-saturated soil clays, humic substances and clay-humic complexes. Journal of the Indian Society of Soil Science, 60, 276-280.

[13] Gujrathi, N.P., Haney, B.J., Park, H.J., et al, (2005) Hairy roots of Helianthus annuus a model system to study phtoremediation of tetracycline and oxytetracycline. Biotechnology Progress, 21, 775-780.

[14] Coniglio, M.S., Busto, V.D., Gonzalez, P.S., et al., (2008) Application of Brassica napus hairy root cultures for phenol removal from aqueous solutions. Chemosphere, 72, 1035-1042. http://dx.doi.org/10.1016/j.chemosphere.2008.04.003

[15] Kumar, K., Gupta, S.C., Baidoo, S.K., et al. (2005) Antibiotic uptake by plants from soil fertilized with animal manure. Journal Environmental Quality, 34, 2082-2085. http://dx.doi.org/10.2134/jeq2005.0026

[16] Seo, Y.H., Cho, B., Kang, A., et al. (2010) Antibiotics uptake by plants from soil applied with antibiotic treated animal manure. Korean Journal of Soil Science and Fertilizer, 43, 43-50. 